\title{
Research Paper: The Feasibility of Using Blended Learning in the Curriculum of Speech Therapy at Tehran University of Medical Sciences
}

\author{
Ali Akbar Khosraavi Babadi ${ }^{*}$ (D), Fatemeh Yousefi Ehraz ${ }^{2}$
}

1. Department of Curriculum Planning, Faculty of Psychology and Social Sciences, Central Tehran Branch, Islamic Azad University, Tehran, Iran. 2. Department of Educational Sciences, Faculty of Psychology and Social Sciences, Central Tehran Branch, Islamic Azad University, Tehran, Iran.

\begin{tabular}{|c|c|}
\hline $\begin{array}{l}\text { Use your device to san } \\
\text { and read the article online }\end{array}$ & Chtat On Khosravi BabadiAA. Yousefi Ehraz F. The Feasibility of Using Blended Learning in the Curriculum of Sneech \\
\hline 口iriting & $\begin{array}{l}\text { Therapy at Tehran University of Medical Sciences. Journal of Modern Rehabilitation. 2018; 12(3):163-168. http://dx.doi. } \\
\text { org/10.32598/JMR.V12.N3.163 }\end{array}$ \\
\hline ald & d oi ${ }^{\circ}$ http://dx.doi.org/10.32598/JMR.V12.N3.163 \\
\hline
\end{tabular}

Article info:

Received: 29 Nov 2017

Accepted: 25 Mar 2018

Available Online: $01 \mathrm{Jul} 2018$

Keywords:

Electronic learning, Blended Learning, Curriculum planning, Speech therapy

\section{ABSTRACT}

Introduction: The current study aimed at determining the feasibility of using Blended Learning in the curriculum of speech therapy at Tehran University of Medical Sciences. The subjects consisted of 48 undergraduate students, 25 undergraduate students, $22 \mathrm{PhD}$. students, and six faculty members selected by random sampling method using Morgan table. Faculty members were also counted.

Materials and Methods: A researcher-made hybrid learning questionnaire was employed to collect data. In the descriptive section, frequency distribution tables, charting, and calculation of central and distribution indices were employed. In the inferential statistics, the KolmogorovSmirnov test was employed to investigate the normal distribution of the variables, and the single-sample t-test to evaluate the research hypotheses.

Results: The results of the evaluation showed that Blended Learning speech therapy curriculum was very important in the combination of speech learning, but from the point of view of speech therapy respondents, the Blended Learning is less used now.

Conclusion: In this regard, the students of the Department of Speech Therapy, Tehran University of Medical Sciences, believed that the combination of high-quality learning speech therapy was of high importance. On the other hand, the highest importance from the viewpoint of the students and faculty members of the Faculty of Rehabilitation, Tehran University of Medical Sciences, was related to educational goals.

\section{Introduction}

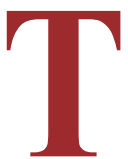

oday's world is rapidly in change and evolution. One of the fields that are severely affected by technological changes is education and learning. Concurrent with the development of new technologies in the field of education, new styles of educational activities enter the arena, which today are called Blended Learning as a method that includes face-to-face learning, live electronic learning,

* Corresponding Author:

Ali Akbar Khosraavi Babadi, PhD.

Address: Department of Curriculum Planning, Faculty of Psychology and Social Sciences, Central Tehran Branch, Islamic Azad University, Tehran, Iran. Tel: +98 (912) 3454300

E-mail:ali.khosravi_babadi@iauctb.ac.ir 
and learning through special methods. According to the ascending progress of rehabilitation sciences and considering both the theoretical and clinical sciences nature of such fields, new approaches toward academic education in these fields are required.

This type of learning is growing in the higher education environments of the developed countries and is an essential part of education and training. Due to the significant increase in the level of knowledge, the obsoleteness of information produced several years ago, the need for updating scientific information and increase in the quantity of learners, the limited physical facilities, the educational costs, the need for equitable education at different levels and layers of society, and despite the benefits of blended training including increased efficiency, cost effectiveness, and flexibility of the teaching method at any time and place, it is important to find out to what extent can the Blended Learning be employed in the curriculum that as it increases, it also improves the quality level.

Some studies are made in this field including the one by Salehi Omran and Salari concluding that the Blended Learning with the merits of the two traditional and electronic education approaches can increase the effectiveness of learning, ease of access to educational materials, and the cost effectiveness. Also, due to providing different opportunities to learn, aside from the increase in attractiveness of education, the personal differences of learners are also attended to, since not all people learn in the same way and hence, it is required to employ different methods for education [1].

Seyedi and Yaghoubi reported that the design and implementation of Blended Learning in rehabilitation fields show that initially the need analysis should be conducted in the fields of rehabilitation and physiotherapy, and speech therapy. By considering the costs of the plan, localization, and the conditions of Iran regarding clinical recovery and updating the information and clinical skills, it is recommended to implement this type of education [2].

Results of the study by Mohammadi et al. evaluating the effect of blended education on the success and satisfaction of the learners in the technical and professional education system, showed that the learners were more significantly satisfied with learning through blended method than the traditional education (face-toface). Therefore, by considering the valuable position of blended education in increasing the satisfaction and success of learners of technical and professional courses, employing this approach can be included among the development program for technical and professional education [3].

The study conducted by Kiviniem on public health graduates of the Department of Community Health and Health Behavior, the University of Buffalo in the United States concluded that the students preferred to have Blended Learning as compared to traditional learning and $83 \%$ of the students were favorably disposed toward blended approach, while only $10 \%$ of the students voted positive for traditional approach [4]. In the study by Charles Dziuban et al. on the Blended Learning of emerging new technology, it was concluded that although the Blended Learning arises from the modern education technologies, its development definitely relates to the contemporary information and communications technologies [5].

In the study by Coyne, the simulated videos as a Blended Learning resource increased the students' understanding of family assessment and were worth incorporating into future development of courses [6]. Results derived from the study by Herbert on transforming this introductory pathology course demonstrated a model to employ Blended Learning in large group teaching sessions, which achieved high levels of completion, satisfaction, and value for learning [7].

In the study by McCutcheon, Blended Learning provides added pedagogical value when compared to online learning in terms of teaching clinical supervision skills to undergraduate nurses. The evidence is the timely given worldwide calls to expand clinical skills supervision in undergraduate health professional education to improve quality of care and patient safety [8].

Since health environments are rapidly changing, it is necessary to acquaint health researchers in rehabilitation field with new methods of learning knowledge and clinical skills related to their field of study in order to have more effective functions. Therefore, according to the researchers, the feasibility study on the employment of Blended Learning is of high importance to determine the extent that the Blended Learning can be used in the curriculum, while the quantity is increased the quality would not be altered, and even elevated. Therefore, the current study aimed at finding out if there is the possibility of using Blended Learning in the curriculum planning of speech therapy courses of Tehran University of Medical Sciences. 


\section{Materials and Methods}

The current study employed the survey method, which is among the quantitative methods. In general, descriptive studies consider some data collection methods in terms of the society. This method aimed at obtaining the significance level of the acquired indicators of Blended Learning in curriculum designing of speech therapy at Tehran University of Medical Sciences from the point of view of the students and faculty members of this university (desirable situation), and also the level of using these indicators in the class curriculum currently used at the studied department, and eventually examining the viewpoints of faculty members and the students to determine the significant and less significant points in organizing Blended Learning at the Department of Rehabilitation of Tehran University of Medical Sciences.

The measuring tool was the questionnaire prepared with six indicators. Need Assessment, educational goals, learning, content and the curriculum course plan, equipment and infrastructures, and the evaluation. Statistical population of the study included all of the students of speech therapy in the first semester of the academic year 2017-2018 studying at three levels of Bachelor's degree (undergraduate) (54 students), Master's degree (graduate) (26 students) and $\mathrm{PhD}$. (doctorate) (22 students), and members of the scientific faculty of the same field at the Rehabilitation Department of Tehran University of Medical Sciences. The stratified sampling method was employed. After obtaining permission to execute the study at this department, the questionnaires were distributed and filled out.
The questionnaire has six indicators including need assessment indicator, educational goals, learning, content and course plan, equipment, and evaluation proportionate with those indicators questions set forth. The indicators were set up in the two situations of the desirable and the current situation based on the level of the significant indicators and the level of satisfaction of the current situation in execution of the indicators in the current curriculum. In the current study, the descriptive and analytical statistics were employed to analyze the data. In the analytical statistics, the Kolmogorov-Smirnov test was employed to examine the normal distribution of the research variables, the single sample t-test to test the research hypotheses, and Friedman Test for ranking.

\section{Results}

The Blended Learning indicators in the two situations of significance level and satisfaction level from the view points of the faculty members and the students were examined and the distance between the current situation and the desirable situation was studied.

According to the Figures 1 and 2, it can be concluded that both the faculty members and the students selected the options, few and very few for the current situation. In other words most of them stated that in the field of speech therapy the Blended Learning is rarely used at present.

\section{Discussion}

As already mentioned, it was concluded that priorities in various areas of Blended Learning were different. Thus, current study aimed at investigating the priorities of important Blended Learning indicators in speech

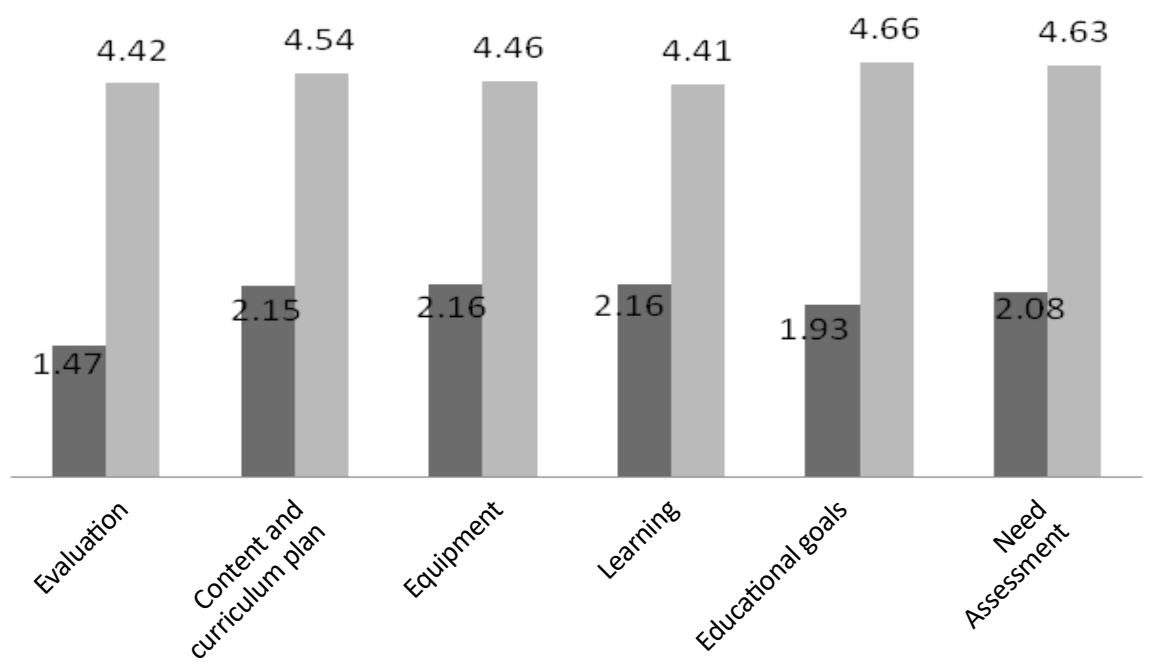

Figure 1. Comparison in the current situation and the optimum situation 


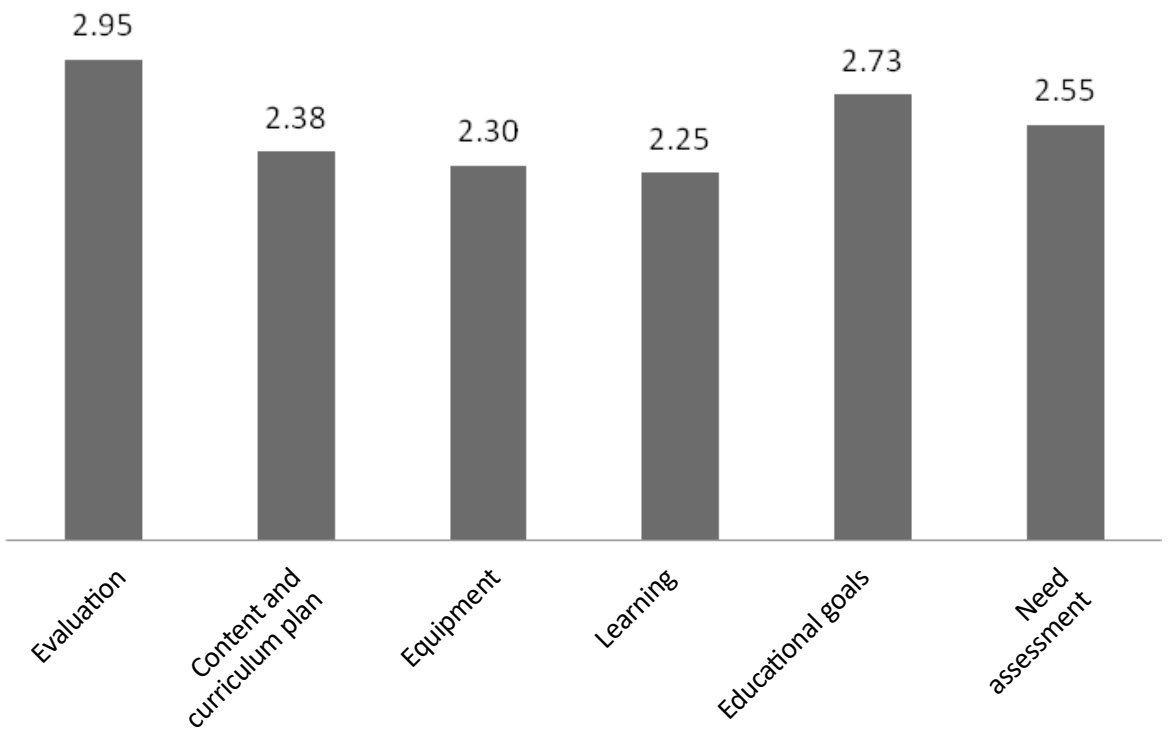

Figure 2. The distance between the optimum situation and the current situation

therapy in order to determine which indicators need further investigation.

As observed in Figure 1, there was a significant difference between the significance level and the degree of satisfaction with regard to Blended Learning. Results of the evaluation showed that in the curriculum planning for the speech therapy field, Blended Learning was of great significance; however, from the view point of the respondents, at present, Blended Learning was scarcely used in the speech therapy field.

According to the nature of this field and the current instructor-centered education, the equipment and the high costs of clinical education, the need is felt for a fundamental evolution in this field. And by considering the strategy of this field and the integration of instructorcentered education and student-centered education and also continuous self learning, it seems that implementing the Blended Learning can cover the educational goals of this field. It is noteworthy that Blended Learning with the merits of traditional learning and electronic learning can be an appropriate method for this field of study that has theoretical and clinical curriculum.

In fact, the obtained statistical results also indicate that the significance level of Blended Learning indicators was positive from the point of view of faculty members and students of the field of speech therapy of Tehran University of Medical Sciences, and they believed that Blended Learning could be possibly employed in this field. Therefore, to determine the significance level of the Blended Learning indicators they selected the options: much, and very much.

According to the obtained statistical results, to execute the Blended Learning, there are priorities, and indicators of educational goals and need assessment are of superior priority from the view points of faculty members and students. Meanwhile, considering the practicality of this field and the necessity to implement practical techniques on the patient, environments should be created similar to the real situation to acquaint the learners with real situations, which require strengthening and reinforcing the infrastructures of equipment, physical environments, and trained and experienced manpower. Therefore, by considering these points and budgeting properly, this important achievement can be accessed.

According to the statistical results it can be concluded that among the needed indicators to execute Blended Learning, there were priorities and the educational goals and need assessment had higher priority from the view points of faculty members and students (Figure 2). In general, the goals of curriculum planning were the first steps of curriculum planning process and determining the goals in a more exact and clearer way can lead the planner to having a more useful criterion to select the content.

According to the existence of practical courses in this field and the necessity to implement practical techniques on the patient, environments similar to real situations should be created to acquaint learners with real situa- 
tions that requires strengthening the infrastructures of equipment, providing physical environments, training experienced manpower, and supplying electronic content including the content quality, supporting the learners, inclining and motivating the learners; the learners characteristics, the flexibility of time and place in the education process, access to updated resources, interests of the learners, and the processes related to it should also be considered.

Therefore, by considering these issues and budgeting properly, this important achievement can be accessed and considering that need assessment is a systematic process to determine goals, the process to recognize and identify important needs and provide the grounds to meet the needs in curriculum planning should be carefully considered.

\section{Ethical Considerations}

Compliance with ethical guidelines

This study was approved by the Ethics Committee of Islamic Azad University, Central Tehran Branch.

Funding

This research did not receive any specific grant from funding agencies in the public, commercial, or not-forprofit sectors.

\section{Authors' contributions}

All authors contributed in preparing this article.

\section{Conflict of interest}

The authors declared no conflict of interest.
[4] Kiviniemi MT. Effects of a Blended Learning approach on student outcomes in a graduate-level public health course. BMC Medical Education. 2014; 14:47. [DOI:10.1186/14726920-14-47] [PMID] [PMCID]

[5] Dziuban C, Graham CR, Moskal PD, Norberg A, Sicilia $\mathrm{N}$. Blended Learning: The new normal and emerging technologies. International Journal of Educational Technology in Higher Education. 2018; 15(1):3-19. [DOI:10.1186/s41239-0170087-5]

[6] Coyne E, Frommolt V, Rands H, Kain V, Mitchell M. Simulation videos presented in a Blended Learning platform to improve Australian nursing students' knowledge of family assessment. Nurse Education. 2018; 66:96-102. [DOI:10.1016/j nedt.2018.04.012]

[7] Herbert C, Velan GM, Pryor WM, Kumar RK. A model for the use of Blended Learning in large group teaching sessions. BMC Medical Education. 2017; 17(1):197. [DOI:10.1186/ s12909-017-1057-2]

[8] McCutcheon K, O'Halloran P, Lohan M. Online learning versus Blended Learning of clinical supervisee skills with pre-registration nursing students: A randomised controlled trial. International Journal of Nursing Studies. 2018; 82:30-9. [DOI:10.1016/j.ijnurstu.2018.02.005]

\section{References}

[1] Salehi Omran E, Salari Z. [Blended Learning a new approach in developing teaching and learning process (Persian)]. Education Strategies in Medical Sciences. 2012; 5(1):69-75.

[2] Seyedi M, Yaghoubi Z. [Designing and implementing Blended Learning in the field of rehabilitation (Persian)]. Interdisciplinary Journal of Virtual Learning in Medical Sciences. 2012; 3(2):42-50.

[3] Mohammadi M, Marzooghi R, Salimi Gh, Mansoori S. [The effect of Blended Learning approach on learner's success and satisfaction in technical/vocational education (Persian)] Studies in Learning \& Instruction. 2017; 9(1):91-108 
This Page Intentionally Left Blank 